\title{
Estimasi Emisi Gas Karbondioksida (Co2) Dari Sektor Limbah Padat Di Kabupaten Karangasem Dengan Metode FIRST ORDER DECAY (FOD)
}

\author{
Estimated Emissions of Carbon Dioxide (Co2) from Solid Waste Sector In Kabupaten \\ Karangasem With FIRST ORDER DECAY (FOD) Method
}

\author{
Affan Irfan Fauziawan \\ Program Studi Sistem Komputer, STIMIK STIKOM Bali, Renon, Denpasar Sel., Kota Denpasar, Bali \\ Email:fauziawan@yahoo.com
}

\begin{abstract}
Climate change has become a global issue and to address it involves various countries and various disciplines. The response made by the Indonesian government in responding to the issue of climate change and global warming is contained in Presidential Regulation No. 61 of 2011 on the National Action Plan for Greenhouse Gas Emission Reduction (RAN-GRK) and Presidential Regulation no. 71 Year 2012 on the Implementation of National GHG Emission Inventory. GHG inventory in the district-level solid wastes sector needs to be done, to determine the estimated GHG emissions generated. This study aims to estimate GHG emissions from the solid waste sector in Karangasem regency, Bali. In this study, using the First Order Decay (FOD) method contained in IPCC 2006 GL. From the research results it is known that TPA in Karangasem district is still open dumping, which has Methane Correction Factor (MCF) of 0.8 . The amount of solid waste (solid waste) that goes into landfill in 2010 - 2015 has increased from $37,419 \mathrm{m3}$ to 43,212 m3. DOC (Degradable Organic Carbon) for the type of garbage entering TPA (heavy fraction) ie food waste 0.38 , paper waste 0.44 , garden waste 0.49 , textile garbage 0.3 , wood waste 0.5 , garbage leather / rubber 0.47 . Based on the calculation, the estimated amount of solid waste GHG emissions generated in Karangasem regency, from year 2011 amounted to 2,918 tons CO2e and continues to increase each year, until 2015 emissions generated 9.153 tons CO2e / year.

Keywords: Climate change, CO2 emissions, solid waste, IPCC, DOC
\end{abstract}

\begin{abstract}
Abstrak
Perubahan iklim telah menjadi persoalan global dan untuk mengatasinya melibatkan berbagai negara dan berbagai disiplin ilmu. Respon yang dilakukan pemerintah Indonesia di dalam menanggapi isu perubahan iklim dan pemanasan global tertuang dalam Peraturan Presiden Nomor 61 Tahun 2011 tentang Rencana Aksi Nasional Penurunan Emisi Gas Rumah Kaca (RAN-GRK) dan Peraturan Presiden No. 71 Tahun 2012 tentang Penyelenggaraan Inventarisasi Emisi GRK Nasional. Inventarisasi GRK di sektor limbah padat tingkat kabupaten ini perlu dilakukan, untuk mengetahui estimasi emisi GRK yang dihasilkan. Penelitian ini bertujuan untuk mengestimasi emisi GRK dari sektor limbah padat di Kabupaten Karangasem, Bali. Pada penelitian ini, menggunakan metode First Order Decay (FOD) yang terdapat dalam IPCC 2006 GL. Dari hasil penelitian diketahui bahwa TPA di kabupaten Karangasem masih bersifat open dumping, yang memiliki Methane Correction Factor (MCF) sebesar 0,8. Jumlah sampah (limbah padat) yang masuk ke TPA tahun 2010 - 2015 mengalami peningkatan dari $37.419 \mathrm{~m}^{3}$ menjadi $43.212 \mathrm{~m}^{3}$. DOC (Degradable Organic Carbon) untuk jenis sampah yang masuk ke TPA (fraksi berat) yaitu sampah makanan 0,38, sampah kertas 0,44 , sampah taman 0,49 , sampah kain tekstil 0,3, sampah kayu 0,5, sampah kulit/karet 0,47. Berdasarkan hasil perhitungan, estimasi besarnya emisi GRK sektor limbah padat yang dihasilkan di kabupaten Karangasem, dari tahun 2011 sebesar 2.918 ton CO2e dan terus meningkat setiap tahunnya, hingga tahun 2015 emisi yang dihasilkan sebesar 9.153 ton CO2e/tahun.
\end{abstract}

Kata Kunci: Perubahan iklim, Emisi CO2, Limbah padat, IPCC, DOC 


\section{Pendahuluan}

Perubahan iklim telah menjadi persoalan global dan untuk mengatasinya melibatkan berbagai negara dan berbagai disiplin ilmu. Dampak perubahan iklim mulai dirasakan di berbagai belahan bumi. Peningkatan temperatur udara dan peningkatan permukaan air laut sebagai dampaknya, sudah memberikan ancaman bagi kehidupan, terutama bagi ekosistem pesisir yang beresiko mengalami banjir dan erosi. Perubahan iklim mempengaruhi berbagai aspek kehidupan, antara lain aspek lingkungan, aspek sosial ekonomi, aspek kesehatan, serta aspek lainnya. Gas rumah kaca (GRK) merupakan gas di atmosfir yang berfungsi menyerap radiasi infra merah dan ikut menentukan suhu atmosfir. Adanya berbagai aktivitas manusia, khususnya sejak era praindustri, menyebabkan emisi GRK ke atmosfer mengalami peningkatan yang sangat tinggi, sehingga meningkatkan konsentrasi GRK di atmosfer. Hal ini menyebabkan timbulnya masalah pemanasan global dan perubahan iklim.

Menurut Konvensi Kerja Perserikatan Bangsa-Bangsa tentang Perubahan Iklim (United Nation Framework Convention on Climate Change/UNFCCC), sistem iklim dalam hubungannya dengan perubahan iklim didefinisikan sebagai totalitas atmosfer, hidrosfer, biosfer, dan geosfer dengan interaksinya. Sedangkan perubahan iklim dinyatakan sebagai perubahan iklim yang dipengaruhi langsung atau tidak langsung oleh aktivitas manusia yang mengubah komposisi atmosfer, yang akan memperbesar keragaman iklim teramati pada periode yang cukup panjang. Perubahan iklim terutama disebabkan oleh meningkatnya konsentrasi $\mathrm{CO}_{2}$ dan GRK lainnya. Meningkatnya konsentrasi $\mathrm{CO}_{2}$ dan GRK lainnya tersebut diketahui merupakan akibat dari sejumlah aktivitas antropogenik, terutama akibat dari pembakaran bahan bakar fosil dalam produksi energi dan kegiatan alih guna lahan. Jenis/tipe GRK yang keberadaanya di atmosfer berpotensi menyebabkan perubahan iklim global adalah $\mathrm{CO}_{2}, \mathrm{CH}_{4}, \mathrm{~N}_{2} \mathrm{O}, \mathrm{HFCs}$, PFCs, dan $\mathrm{SF}_{6}$. Dari semua jenis gas tersebut, GRK utama ialah $\mathrm{CO}_{2}, \mathrm{CH}_{4}$, dan $\mathrm{N}_{2} \mathrm{O}$. Dari ketiga jenis gas ini, yang paling banyak kandungannya di atmosfer ialah $\mathrm{CO}_{2}$ sedangkan yang lainnya sangat sedikit sekali.

Pada Konferensi Tingkat Tinggi (KTT) Bumi di Rio de Janeiro tahun 2002, menghasilkan konvensi perubahan iklim dengan tujuan untuk menstabilisasi konsentrasi gas-gas rumah kaca di atmosfer pada tingkat yang tidak membahayakan sistem iklim. Respon yang dilakukan pemerintah Indonesia di dalam menanggapi isu perubahan iklim dan pemanasan global tertuang dalam Peraturan Presiden Nomor 61 Tahun 2011 tentang Rencana Aksi Nasional Penurunan Emisi Gas Rumah Kaca (RANGRK). Pada Perpres tersebut terdapat komitmen pemerintah Indonesia untuk menurunkan emisi GRK sebesar 26\% dari Business as Usual (BaU) pada tahun 2020. RAN-GRK yang diprogramkan oleh pemerintah merupakan gabungan dari RAD-GRK (Rencana Aksi Daerah Penurunan Emisi Gas Rumah Kaca). Pada Konferensi Tingkat Tinggi (KTT) yang diselenggarakan pada tahun 2015 di Paris (COP 21 Paris), menghasilkan beberapa pokok-pokok Kesepakatan Paris (Paris Agreement) diantaranya yaitu adanya kesepakatan dari masing-masing negara peserta untuk membatasi kenaikan suhu global dibawah $2^{\circ} \mathrm{C}$ dari tingkat pre-industri dan melakukan upaya untuk membatasinya hingga dibawah $1,5^{\circ} \mathrm{C}$. Selain itu setiap negara didorong untuk mendukung pendekatan kebijakan dan insentif positif untuk aktivitas penurunan emisi.

Perubahan iklim telah menjadi persoalan global dan untuk mengatasinya melibatkan berbagai negara dan berbagai disiplin ilmu. Dampak perubahan iklim mulai dirasakan di berbagai belahan bumi. Peningkatan temperatur udara dan peningkatan permukaan air laut sebagai dampaknya, sudah memberikan ancaman bagi kehidupan, terutama bagi ekosistem pesisir yang beresiko mengalami banjir dan erosi. Perubahan iklim mempengaruhi berbagai aspek kehidupan, antara lain aspek lingkungan, aspek sosial ekonomi, aspek kesehatan, serta aspek lainnya. Gas rumah kaca (GRK) merupakan gas di atmosfir yang berfungsi menyerap radiasi infra merah dan ikut menentukan suhu atmosfir. Adanya berbagai aktivitas manusia, khususnya sejak era praindustri, menyebabkan emisi GRK ke atmosfer mengalami peningkatan yang sangat tinggi, 
sehingga meningkatkan konsentrasi GRK di atmosfer. Hal ini menyebabkan timbulnya masalah pemanasan global dan perubahan iklim.

Menurut Konvensi Kerja Perserikatan Bangsa-Bangsa tentang Perubahan Iklim (United Nation Framework Convention on Climate Change/UNFCCC), sistem iklim dalam hubungannya dengan perubahan iklim didefinisikan sebagai totalitas atmosfer, hidrosfer, biosfer, dan geosfer dengan interaksinya. Sedangkan perubahan iklim dinyatakan sebagai perubahan iklim yang dipengaruhi langsung atau tidak langsung oleh aktivitas manusia yang mengubah komposisi atmosfer, yang akan memperbesar keragaman iklim teramati pada periode yang cukup panjang. Perubahan iklim terutama disebabkan oleh meningkatnya konsentrasi $\mathrm{CO}_{2}$ dan GRK lainnya. Meningkatnya konsentrasi $\mathrm{CO}_{2}$ dan GRK lainnya tersebut diketahui merupakan akibat dari sejumlah aktivitas antropogenik, terutama akibat dari pembakaran bahan bakar fosil dalam produksi energi dan kegiatan alih guna lahan. Jenis/tipe GRK yang keberadaanya di atmosfer berpotensi menyebabkan perubahan iklim global adalah $\mathrm{CO}_{2}, \mathrm{CH}_{4}, \mathrm{~N}_{2} \mathrm{O}, \mathrm{HFCs}$, PFCs, dan $\mathrm{SF}_{6}$. Dari semua jenis gas tersebut, GRK utama ialah $\mathrm{CO}_{2}, \mathrm{CH}_{4}$, dan $\mathrm{N}_{2} \mathrm{O}$. Dari ketiga jenis gas ini, yang paling banyak kandungannya di atmosfer ialah $\mathrm{CO}_{2}$ sedangkan yang lainnya sangat sedikit sekali.

Pada Konferensi Tingkat Tinggi (KTT) Bumi di Rio de Janeiro tahun 2002, menghasilkan konvensi perubahan iklim dengan tujuan untuk menstabilisasi konsentrasi gas-gas rumah kaca di atmosfer pada tingkat yang tidak membahayakan sistem iklim. Respon yang dilakukan pemerintah Indonesia di dalam menanggapi isu perubahan iklim dan pemanasan global tertuang dalam Peraturan Presiden Nomor 61 Tahun 2011 tentang Rencana Aksi Nasional Penurunan Emisi Gas Rumah Kaca (RANGRK). Pada Perpres tersebut terdapat komitmen pemerintah Indonesia untuk menurunkan emisi GRK sebesar 26\% dari Business as Usual (BaU) pada tahun 2020. RAN-GRK yang diprogramkan oleh pemerintah merupakan gabungan dari RAD-GRK (Rencana Aksi Daerah Penurunan Emisi Gas Rumah Kaca). Pada Konferensi Tingkat Tinggi (KTT) yang diselenggarakan pada tahun 2015 di Paris (COP 21 Paris), menghasilkan beberapa pokok-pokok Kesepakatan Paris (Paris Agreement) diantaranya yaitu adanya kesepakatan dari masing-masing negara peserta untuk membatasi kenaikan suhu global dibawah $2^{0} \mathrm{C}$ dari tingkat pre-industri dan melakukan upaya untuk membatasinya hingga dibawah $1,5^{\circ} \mathrm{C}$. Selain itu setiap negara didorong untuk mendukung pendekatan kebijakan dan insentif positif untuk aktivitas penurunan emisi.

\section{Metode Penelitian}

\section{Penentuan Metodologi}

Terdapat 2 (dua) metode untuk penentuan emisi methane $\left(\mathrm{CH}_{4}\right)$ dari TPA, yaitu:

1. Metode Neraca Massa

2. Metode First Order Decay (FOD).

Penghitungan emisi GRK dengan Metode Neraca Massa dapat dilakukan, tetapi hasil yang diperoleh tidak seakurat dengan metode FOD. Sehingga, merujuk IPCC 2006 GL, penghitungan emisi GRK dari pengolahan limbah padat di TPA menggunakan metode FOD. Metode neraca massa tidak digunakan karena hasil dari metode neraca massa tidak dapat dibandingkan dengan metode FOD yang mempunyai hasil penghitungan emisi tahunan yang lebih akurat. Metode penghitungan FOD ini lebih akurat karena bisa sampai menghitung Methane Recovery, dimana methane yang dihasilkan oleh limbah padat di TPA bisa dimanfaatkan sebagai pembangkit listrik yang ramah lingkungan. (Zurbrugg $\mathrm{C} \mathrm{dkk,} \mathrm{2012)}$

Berdasarkan metode FOD, total emisi gas $\mathrm{CH}_{4}$ pada tahun $\mathrm{T}$ adalah total gas $\mathrm{CH}_{4}$ yang terbentuk pada tahun $\mathrm{T}$ dikoreksi dengan besarnya gas $\mathrm{CH}_{4}$ yang di-recovery untuk dimanfaatkan atau dibakar untuk keamanaan.

Emisi $\mathrm{CH}_{4}$ tahun T, Ggram $=\left[\sum_{\mathrm{x}} \mathrm{CH}_{4}\right.$ generated $\left._{\mathrm{z}, \mathrm{t}}-\mathrm{R}_{\mathrm{T}}\right] \cdot\left(1-0 \mathrm{X}_{\mathrm{T}}\right)$

Keterangan:T: tahun inventarisasi, $\mathrm{X}$ : tipe atau jenis limbah, $\mathrm{R}_{\mathrm{T}}$ : $\mathrm{CH}_{4}$ yang di-recovery untuk dimanfaatkan atau di bakar pada tahun $\mathrm{T}$, Ggram, $\mathrm{OX}_{\mathrm{T}}$ : faktor oksidasi pada tahun $\mathrm{T}$, fraksi, $\mathrm{CH}_{4}$ generated ${ }_{\mathrm{x}}, \mathrm{T}$ : $\mathrm{CH}_{4}$ yang terbentuk pada tahun $\mathrm{T}$ hasil dekomposisi komponen organik jenis tertentu (x) yang tersimpan di dalam limbah padat (DDOC). 
Metodologi perhitungan inventarisasi limbah padat mengacu pada IPCC 2006 dengan menggunakan Tier 2. Data aktivitas yang digunakan dalam perhitungan inventarisasi berasal dari angka default IPCC 2006 dan parameter lokal lainnya yang merupakan hasil survey di daerah tersebut.

Salah satu karakteristik limbah padat yang menentukan laju pembentukan emisi gas metana adalah DOC. DOC adalah karakteristik yang menentukan besarnya gas $\mathrm{CH}_{4}$ yang dapat terbentuk pada proses degradasi komponen (karbon) organik yang ada pada limbah. Pada limbah padat padat kota, DOC limbah padat bulk diperkirakan berdasarkan komposisi (\% berat) limbah padat dan DOC masing-masing komponen limbah padat.

$$
D O C=\Sigma_{i}\left(D O C_{i} * W_{i}\right)
$$

Keterangan: DOC: fraksi degradable organic carbon pada limbah padat bulk, Ggram/Gram Limbah padat, DOCi: fraksi degradable organic karbon pada komponen limbah padat I (basis berat basah), $\mathrm{W}_{\mathrm{i}}$ : fraksi komponen limbah padat jenis i (basis berat basah), $\mathrm{i}=$ komponen limbah padat (misal limbah padat makanan, kertas, kayu, dan lain-lain).

Komponen/komposisi limbah padat kota umumnya bervariasi bergantung jenis kota (metropolitan, kota besar, atau kota kecil), iklim (kelembaban dan curah hujan) dan perilaku/gaya hidup masyarakat di wilayah. Berdasarkan hasil survey komposisi sampah yang dilakukan dalam Pilot Project antara KLH - JICA - ITB - BLH Sumatra Utara - BLH Sumatra Selatan, maka komposisi sampah seperti pada Tabel 1.

$\mathrm{DOC}_{\mathrm{i}}$ dalam basis berat basah dapat dihitung dari $\mathrm{DOC}_{\mathrm{i}}$ dalam basis berat kering dikalikan dengan kandungan bahan kering sebagaimana pada persamaan berikut :

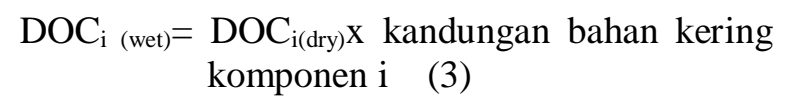

Selain DOC sampah, hal yang harus diketahui untuk menghitung emisi GRK adalah Dry Matter Content (Kandungan Bahan Kering) sampah. Kandungan bahan kering adalah fraksi (\%) berat kering suatu komponen sampah basah, yang dihitung berdasarkan rasio berat kering terhadap berat basah komponen sampah. Kandungan bahan kering ditentukan dengan pendekatan gravimetry (penimbangan berat sampel yang representatif) dan dilakukan untuk setiap jenis komponen sampah yang dianggap memiliki kandungan air. Tidak semua komponen memiliki kandungan air, berdasarkan IPCC2006 GL data default dry matter content sampah plastik, gelas, logam adalah $100 \%$. Berikut adalah DOC dan dry matter content dari berbagai jenis sampah menurut IPCC 2006.

Apabila data jumlah sampah yang masuk ke TPA bukan dalam satuan massa (misal dalam satuan volume, $\mathrm{m}^{3}$ ), maka perlu dikalikan dengan faktor konversi bulk density sampah $\left(\mathrm{kg} / \mathrm{m}^{3}\right)$.

$$
\text { Vs }\left[\mathrm{m}^{3} / \text { tahun }\right] * \mathrm{BD}\left[\mathrm{kg} / \mathrm{m}^{3}\right] * 10^{-6}
$$

Keterangan: Vs = Volume sampah masuk TPA (dari logbook TPA)

Metode untuk menentukan bulk density sampah yaitu :

a) Menimbang kendaraan berisi sampah yang masuk ke TPA

b) Menimbang berat kendaraan kosong (keluar TPA)

c) Mengukur volume bak/container kendaraan sampah

d) Memperkirakan volume sampah aktual berdasarkan pengamatan visual (prosen volume sampah dalam bak)

Bulk Density = hasil rata-rata berat sampah : volume sampah yang masuk TPA

Penghitungan emisi GRK untuk inventarisasi GRK, pada dasarnya dasarnya merujuk pendekatan umum sebagaimana disampaikan pada persamaan berikut:

Tingkat Emisi = Data Aktifitas (AD) $\mathrm{x}$ Faktor Emisi (EF) (5)

Keterangan: AD: besaran kuantitatif kegiatan manusia (anthropogenic) yang melepaskan GRK., EF: faktor yang menunjukkan intensitas emisi GRK per unit aktivitas yang besarnya bergantung kepada karakteristik limbah dan sistem pengolahan limbah. 
Faktor emisi merupakan salah satu komponen penting dalam penghitungan besarnya emisi yang dihasilkan. Faktor emisi untuk penghitungan emisi GRK sektor limbah ini masih menggunakan angka default IPCC. Karena untuk mencari faktor emisi di daerah, harus melakukan waste stream survey terlebih dahulu.

Tabel 1. Komposisi Sampah yang masuk masing-masing TPA

\begin{tabular}{|c|c|c|c|c|}
\hline \multirow{2}{*}{$\begin{array}{l}\text { Komponen } \\
\text { Sampah }\end{array}$} & \multicolumn{4}{|c|}{ Komposisi Sampah, \% Berat Basah } \\
\hline & *Sumatera Selatan & *Sumatera Utara & Rata-Rata & $\begin{array}{l}\text { IPCC } 2006 \text { Guidelines (*) } \\
\text { (South East Asia Region) }\end{array}$ \\
\hline a. Makanan & $59 \%$ & $54 \%$ & $54 \%$ & $43,5 \%$ \\
\hline $\begin{array}{ll}\text { b. } & \text { Kertas + } \\
& \text { Karton + } \\
& \text { Nappies }\end{array}$ & $15 \%$ & $13 \%$ & $14 \%$ & $12,9 \%$ \\
\hline c. Kayu & $3 \%$ & $14 \%$ & $9 \%$ & $9,9 \%$ \\
\hline $\begin{array}{l}\text { d. Kain+ Produk } \\
\text { Tesktil }\end{array}$ & $2 \%$ & $3 \%$ & $2 \%$ & $2,7 \%$ \\
\hline $\begin{array}{l}\text { e. Karet dan } \\
\text { kulit }\end{array}$ & $0 \%$ & $1 \%$ & $0 \%$ & $0,9 \%$ \\
\hline f. Plastik & $19 \%$ & $10 \%$ & $15 \%$ & $7,2 \%$ \\
\hline g. Logam & $0 \%$ & $0 \%$ & $0 \%$ & $3,3 \%$ \\
\hline h. Gelas & $1 \%$ & $1 \%$ & $1 \%$ & $4,0 \%$ \\
\hline i. Lain-lain & $7 \%$ & $7 \%$ & $3 \%$ & $16,3 \%$ \\
\hline TOTAL & $100 \%$ & $100 \%$ & $100 \%$ & $100 \%$ \\
\hline
\end{tabular}

Sumber: Manual survey komposisi sampah dan dry matter content (Pilot Project JICA-KLH-ITB-BLH Sumatera Utara, BLH Sumatera Selatan), diolah dari $4^{\text {th }}$ Technical training on the Pilot Project- Waste Sector (Palembang, 19 Desember 2011 dan Medan, 15 Desember 2011).

Tabel 2. Data DOC dan dry matter content sampah kota.

\begin{tabular}{|c|c|c|c|c|c|c|c|c|c|}
\hline \multirow[t]{2}{*}{$\begin{array}{l}\text { Komponen } \\
\text { Sampah }\end{array}$} & \multirow{2}{*}{$\begin{array}{l}\begin{array}{c}\text { Dry matter } \\
\text { content (\% } \\
\text { berat basah) }\end{array} \\
\text { Default }\end{array}$} & \multicolumn{2}{|c|}{$\begin{array}{l}\text { DOC (\% berat } \\
\text { basah) }\end{array}$} & \multicolumn{2}{|c|}{$\begin{array}{l}\text { DOC content in } \\
\% \text { of dry waste }\end{array}$} & \multicolumn{2}{|c|}{$\begin{array}{l}\text { Total carbon in } \\
\% \text { of dry weight }\end{array}$} & \multicolumn{2}{|c|}{$\begin{array}{l}\text { Fossils carbon } \\
\text { Fraction in \% of } \\
\text { total carbon }\end{array}$} \\
\hline & & Default & Range & Default & Range & Default & Range & Default & Range \\
\hline Kertas/Karton & 90 & 40 & $36-45$ & 44 & $40-50$ & 46 & $42-50$ & 1 & $0-5$ \\
\hline Tekstil & 80 & 24 & $20-40$ & 30 & $25-50$ & 40 & $25-50$ & 20 & $0-50$ \\
\hline $\begin{array}{l}\text { Limbah } \\
\text { makanan }\end{array}$ & 40 & 15 & $8-20$ & 38 & $20-50$ & 38 & $20-50$ & - & - \\
\hline Limbah kayu & 85 & 43 & $39-46$ & 50 & $46-54$ & 50 & $46-54$ & - & - \\
\hline $\begin{array}{l}\text { Limbah } \\
\text { taman/kebun }\end{array}$ & 40 & 20 & $18-22$ & 49 & $45-55$ & 49 & $45-55$ & 0 & 0 \\
\hline Napies & 40 & 24 & $18-22$ & 60 & $44-80$ & 70 & $54-90$ & 10 & 10 \\
\hline $\begin{array}{l}\text { Karet dan } \\
\text { Kulit }\end{array}$ & 84 & (39) & (39) & (39) & (39) & 67 & 67 & 20 & 20 \\
\hline Plastik & 100 & - & - & & & 75 & $67-85$ & 100 & $95-100$ \\
\hline Logam & 100 & - & - & & & NA & NA & NA & NA \\
\hline Gelas & 100 & - & - & & & NA & NA & NA & NA \\
\hline $\begin{array}{l}\text { Lain-lain } \\
\text { (inert waste) }\end{array}$ & 90 & - & - & & & 3 & $8-5$ & 100 & $50-100$ \\
\hline
\end{tabular}




\section{Hasil dan Pembahasan}

Pengolahan limbah padat (sampah) di TPA Kab. Karangasem merupakan TPA tipe open dumping. TPA Kab. Karangasem juga tidak memiliki jembatan timbang, sehingga data kendaraan yang berisikan sampah dan sumber sampah perlu dicatat. Basis perhitungan volume adalah kapasitas (volume) kendaraan (berdasarkan spesifikasi) dan persentase volume aktual berdasarkan pengamatan visual (misal : $75 \%$ dari kapasitas, $125 \%$ dari kapasitas). Konversi data volume menjadi data berat sampah menggunakan persamaan (4) dan faktor konversi (bulk density sampah).

Berdasarkan hasil survey yang dilakukan ke Dinas Lingkungan Hidup dan Dinas Kebersihan dan Pertamanan Kabupaten Karangasem, diperoleh hasil bahwa masyarakat Kabupaten Karangasem tidak semuanya membuang sampah di TPS ataupun ke TPA. Ada perilaku masyarakat yang membuang sampah dengan cara dibakar, ditimbun dan dibuang pada tempat tertentu. Sedangkan jumlah sampah yang terangkut ke TPA dari tahun 2010 sampai dengan tahun 2015 dapat dilihat pada Tabel 3.

Contoh :

Menggunakan data tahun 2010, diketahui volume sampah adalah $37.419 \mathrm{~m}^{3}$. Untuk perhitungan inventarisasi emisi GRK, data volume tersebut akan dikonversikan terlebih dahulu menjadi satuan berat (ton). Diketahui, untuk densitas sampah nasional adalah $347 \mathrm{~kg} / \mathrm{m}^{3}$ (Pedoman Inventarisasi GRK KLH, 2012). Menggunakan persamaan (4), maka penyelesaiannya adalah sebagai berikut :

$W($ ton $)=\frac{37419 \mathrm{~m}^{\mathrm{a}} \times 347^{\mathrm{kg}} / \mathrm{m}^{\mathrm{a}}}{1000}=12.984 \mathrm{ton}$

Dengan cara yang sama, maka didapatkan data berat sampah yang masuk ke TPA Kab. Karangase.

Peningkatan volume sampah yang terangkut/dihasilkan berbanding lurus dengan jumlah penduduk Kab. Karangasem dari tahun
2010 sampai dengan tahun 2015. Hal tersebut terlihat dari Tabel 4.

Dari Tabel 5 bisa dilihat bahwa setiap tahun, jumlah penduduk di Kab. Karangasem selalu mengalami kenaikan, sehingga sampah yang dihasilkan juga semakin meningkat. Faktor-faktor yang berpengaruh dalam penghitungan inventarisasi GRK diantaranya adalah komposisi limbah padat dan kandungan bahan kering (dry matter content). Pada penelitian ini data komposisi limbah padat dan kandungan bahan kering (dry matter content) menggunakan angka default IPCC2006 dan angka hasil survey pada pilot project Kementrian Lingkungan Hidup.

Perhitungan emisi GRK menggunakan persamaan (1).

\section{Contoh : Tahun 2011}

Dari hasil perhitungan didapatkan emisi GRK yang dihasilkan adalah sebesar 0,1390 Gg. Kemudian di konversikan menjadi $=(0,1390)$ $\mathrm{Gg} \times 1000=139$ ton $\mathrm{CH} 4$.

Tahun 2010 (Tabel 6) belum terhitung untuk emisi yang dihasilkan, ini karena pada tahun 2010 baru mulai adanya pencatatan secara berkala oleh TPA Kab. Karangasem (Tabel 7. dan Gambar 1). Kemudian data tersebut dikonversikan menjadi satuan ton $\mathrm{CO} 2$ dimana menurut rekomendasi dari UNFCCC nilai potensi pemanasan global, besarnya 1 methane sama dengan 21-25 kali karbondioksida, maka didapatkan emisi GRK.

Dari Gambar 1, dapat disimpulkan bahwa setiap tahun, di Kabupaten Karangasem tren emisi yang dihasilkan dari aktifitas di TPA semakin meningkat. Hal ini juga dipengaruhi oleh jumlah penduduk Kabupaten Karangasem yang semakin meningkat dari tahun 2010 sampai tahun 2015. Dengan mengetahui inventarisasi emisi GRK ini, maka diharapkan para stakeholder dapat mengambil langkah nyata untuk mengurangi emisi GRK tersebut. Hal ini dikarenakan semakin besar emisi GRK yang dihasilkan, maka hal tersebut dapat memicu terjadinya pemanasan global (global warming). 
Affan Irfan Fauziawan

Tabel 3. Volume sampah yang terangkut ke TPA Kab. Karangasem

\begin{tabular}{cc}
\hline \hline Tahun & Volume Sampah $\left(\mathbf{m}^{\mathbf{3}}\right)$ \\
\hline \hline 2010 & 37.419 \\
2011 & 39.454 \\
2012 & 40.601 \\
2013 & 41.745 \\
2014 & 42.786 \\
2015 & 43.212 \\
\hline \hline
\end{tabular}

Tabel 4. Berat Sampah yang masuk ke TPA

\begin{tabular}{ccc}
\hline \hline Tahun & Volume Sampah $\left(\mathbf{m}^{\mathbf{3}}\right)$ & Berat (ton) \\
\hline \hline 2010 & 37.419 & 12.984 \\
2011 & 39.454 & 13.691 \\
2012 & 40.601 & 14.089 \\
2013 & 41.745 & 14.486 \\
2014 & 42.786 & 14.847 \\
2015 & 43.212 & 14.995 \\
\hline \hline
\end{tabular}

Tabel 5. Jumlah Penduduk Kab. Karangasem

\begin{tabular}{cc}
\hline \hline Tahun & Jumlah Penduduk \\
\hline \hline 2010 & 432.791 \\
2011 & 438.475 \\
2012 & 448.537 \\
2013 & 457.204 \\
2014 & 468.096 \\
2015 & 471.820 \\
\hline \hline
\end{tabular}

Tabel 6. Emisi yang dihasilkan (ton $\mathrm{CH} 4$ )

\begin{tabular}{ccc}
\hline \hline Tahun & Emisi GRK yang dihasilkan & Satuan \\
\hline \hline 2010 & 0 & ton $\mathrm{CH}_{4}$ \\
2011 & 139 & ton $\mathrm{CH}_{4}$ \\
2012 & 245 & ton $\mathrm{CH}_{4}$ \\
2013 & 325 & ton $\mathrm{CH}_{4}$ \\
2014 & 387 & ton $\mathrm{CH}_{4}$ \\
2015 & 436 & ton $\mathrm{CH}_{4}$ \\
\hline \hline
\end{tabular}

Tabel 7. Emisi yang dihasilkan dari TPA Kab.Karangasem

\begin{tabular}{ccc}
\hline \hline Tahun & Emisi GRK yang dihasilkan & Satuan \\
\hline \hline 2010 & 0 & ton $\mathrm{CO}_{2}$ \\
2011 & 2.918 & ton $\mathrm{CO}_{2}$ \\
2012 & 5.138 & ton $\mathrm{CO}_{2}$ \\
2013 & 6.815 & ton $\mathrm{CO}_{2}$ \\
2014 & 8.117 & ton $\mathrm{CO}_{2}$ \\
2015 & 9.153 & ton $\mathrm{CO}_{2}$ \\
\hline \hline
\end{tabular}




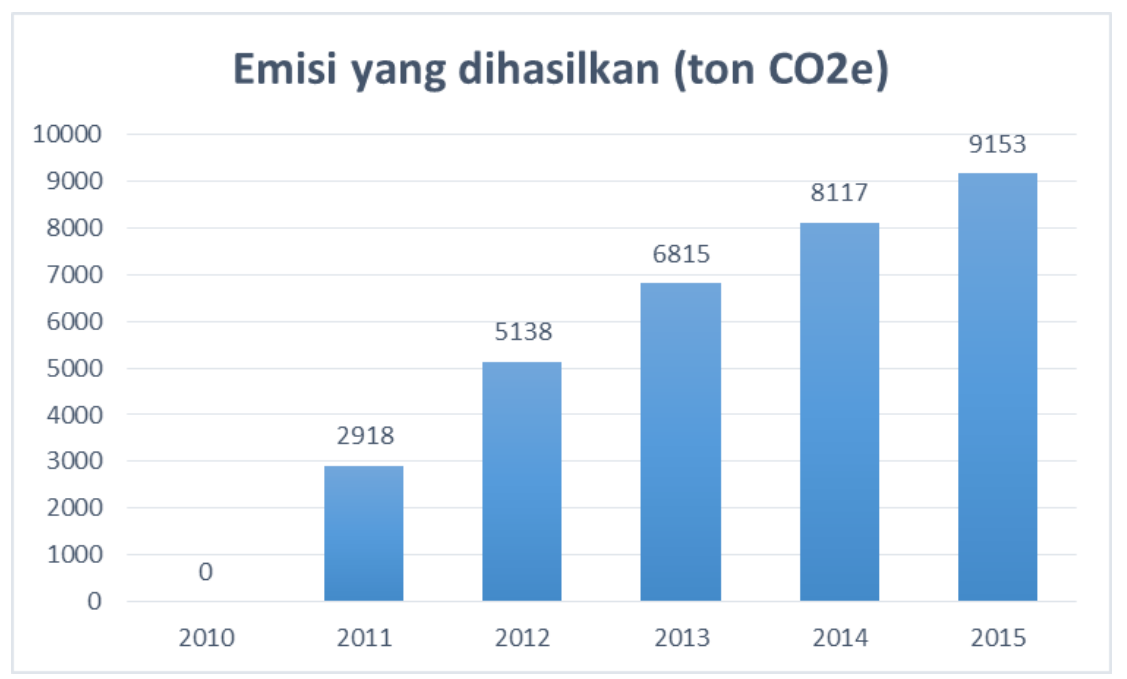

Gambar 1. Grafik emisi yang dihasilkan TPA Kab. Karangasem

\section{Simpulan dan Saran}

\section{Simpulan}

Dari hasil penelitian yang dilakukan dapat ditarik kesimpulan bahwa emisi karbondioksida $\left(\mathrm{CO}_{2}\right)$ yang dihasilkan di Kabupaten Karangasem dari sektor limbah padat perkotaan mengalami peningkatan setiap tahunnnya. Emisi yang dihasilkan pada tahun 2011 sebesar 2.918 ton $\mathrm{CO} 2 \mathrm{e}$ dan pada tahun 2015 meningkat menjadi 9.153 ton CO2e. Hal ini disebabkan karena jumlah sampah yang masuk ke TPA Kabupaten Karangasem juga semakin meningkat dari tahun 2011 sebesar $39.454 \mathrm{~m}^{3}$ menjadi $43.212 \mathrm{~m}^{3}$ di tahun 2015. Peningkatan jumlah sampah di TPA ini juga dipengaruhi oleh jumlah penduduk yang semakin meningkat dari 438.475 jiwa pada tahun 2011 menjadi 471.820 jiwa di tahun 2015.

\section{Saran}

Faktor yang mempengaruhi pada perhitungan estimasi emisi GRK diantaranya yaitu komposisi sampah dan kandungan bahan kering (dry matter content). Pada penelitian ini, data keduanya masih menggunakan data default IPCC2006, dikarenakan belum adanya penelitian atau survey tentang komposisi sampah dan kandungan bahan kering tersebut di Kabupaten Karangasem. Seiring dengan Perpres No 61 Tahun 2011 tentang Rencana Aksi Nasional Penurunan Emisi GRK dan Perpres No 71 Tahun 2011 tentang Penyelenggaraan Inventarisasi
Emisi GRK Nasional, maka diharapkan untuk selanjutnya diadakan penelitian/survey tentang komposisi sampah dan kandungan bahan kering di TPA Kabupaten Karangasem, sehingga proses pelaporan perhitungan emisi GRK kabupaten ini akan naik dari Tier 1 menjadi Tier 2 bahkan bisa ke Tier 3.

\section{Daftar Pustaka}

Badan Pusat Statistik Kabupaten Karangasem. Karangasem Dalam Angka 2015 https://karangasemkab.bps.go.id.

Dinas Lingkungan Hidup Kabupaten Karangasem. Status Lingkungan Hidup Daerah 2015. Pemerintah Provinsi Bali. Bali.

Ebie, Y. dan Kobayashi, T. 2014. Development of Emissions Factor for the Decentralized Domestic Wastewater Treatment for the National Greenhouse Gas Inventory. Journal of Water and Environment Technology, 12 (1): 3341.

Eggleston, H.S., Buendia, L., Miwa, K., Ngara, T. dan Tanabe, K. 2006. 2006 IPCC Guidelines for National Greenhouse Gas Inventories: Volume 5- Waste, National Greenhouse Gas Inventories Programme. Japan: IGES.

Eggleston, H.S., Buendia, L., Miwa, K., Ngara, T. dan Tanabe, K. 2008. 2006 IPCC Guidelines for National Greenhouse Gas Inventories - A primer. National Greenhouse Gas Inventories Programme. Japan: IGES.

Kementerian Lingkungan Hidup. 2012. Pedoman Penyelenggaraan Inventarisasi Gas Rumah Kaca Nasional. Vol. 4. 
MacRae, G. dan Rodic, L. 2015. The Weak Link in Waste Management in Tropical Asia? Solid Waste Collection in Bali. Journal of Habitat International, 50: 310-316

Meidiana, C. dan Gamse, T. 2010. Development of Waste Management Practices in Indonesia. European Journal of Scientific Research, 40. EuroJournals Publishing, Inc. 40(2):pp199-210.

Salsabili, A., Aghajani, M., Saheri, S. dan Ahmad Basri, N.E. 2010. Comprehensive Characteristics of Municipal Solid Waste Generated in the Faculty of Engineering, UKM. World Academy of Science, Engineering and Technology. 70. 2010.

Zurbrugg, C., Gfrerer, M., Ashadi, H., Brenner, W. dan Kuper, D. 2012. Determinants of Sustainability in Solid Waste Manegement - The Gianyar Waste Recovery Project in Indonesia. Journal of Waste Management, 32: 2126-2133. 